\title{
Finite element analysis of non-isothermal warm deep drawing of dual phase steel
}

\author{
T. Pepelnjak ${ }^{1 a}$, B. Kaftanoglu ${ }^{2}$ \\ ${ }^{1}$ Forming Laboratory, Faculty of Mechanical Engineering, University of Ljubljana, Ljubljana, Slovenia \\ ${ }^{2}$ Dept. of Manufacturing Engineering and Metal Forming Center of Excellence, ATILIM University, Incek, Ankara, Turkey
}

\begin{abstract}
Improving the formability of the material is an important issue in the deep drawing process. Heating the material above its recrystallization temperature drastically increases formability but in the case of dual phase (DP) steels it results in the loss of their mechanical properties. To improve the drawing ratio, only the heating of the flange region in the warm temperature range up to $300^{\circ} \mathrm{C}$ was studied on DP600 sheet steel by numerical simulation. Thermo-elastic-plastic FEM analysis of deep drawing at several drawing ratios was performed and compared with experimental results.
\end{abstract}

\section{Introduction}

Modern industrial practice tends towards the minimisation of material use with concurrent improvement of product properties what is in particular emphasised in the automotive industry. In several cases the most important properties are strength, crashworthiness, dynamic properties, bending resistance. These properties are to achieve with proper part design and/or forming technology. However, in the last decade new material development has drastically speeded-up the increase of sheet metal strength and formability of produced parts $[1,2]$. This rapid development of new forming technologies, design concepts and new materials with high hardness or/and good formability was stipulated mainly in the automotive sector where added value of sheet metal parts allow high degree of implemented innovations. Demands on improved strength-to-weight ratio led to the development of various new steel types with improved strengths. Among those steels nowadays mostly so called Advanced High Strength steels (AHSS) are used [2]. They can be classified according to their crystallographic structure into dual phase (DP), complex phase (CP), transformation induced plasticity (TRIP), twinning induced plasticity (TWIP) and martensitic (MART) steels as shown in Figure 1. Additional to here mentioned steels already being used in the industrial practice the third generation AHSS steels [3] with improved strength and ductility are developed which should even exceed the tensile strength of martensitic steels. Despite the intensive development of various steel grades and their processing techniques the predictions of use of various AHSS materials in the automotive industry

a Corresponding author: tomaz.pepelnjak@fs.uni-lj.si favorizes the DP steels as the most used materials until year 2020 [4].

The modern production of stamped parts is composed from several forming processes ranging from cutting, bending, deep drawing etc. where various loading conditions of the material appear simultaneously. In the presented paper, the deep drawing process with a tensioncompression stress state will be analysed more in detail.

Deep drawing process is one of the most widely used sheet metal forming operations enabling the producers manufacturing of complex hollow shapes. The process is mostly performed at room temperature. However, in some cases the material formability needs to be increased to achieve the demanded part geometry. The increase of forming temperature above the recrystallization temperature offers one solution to raise the formability limits of the material. This concept is mainly used when materials with extremely low ductility are applied as it is the case of implementation of martensitic steels - Figure 1 .

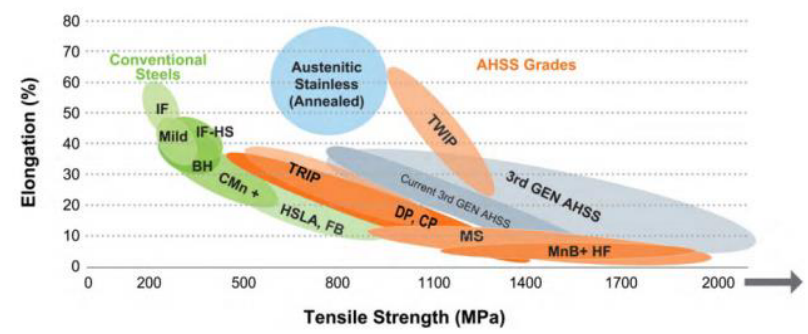

Figure 1. Global formability diagram with position of advanced high strength steels [1].

These steels are formed mainly above the recrystallization temperature with so-called hot stamping 
[4]. On the other side classic dual phase steels could not be formed in hot condition since their characteristic properties results from the combination of the hard martensitic microstructure in the soft ferritic base [2] and this structure is destroyed with material heated above the recrystallization temperature.

The process of deep drawing in one or several operations can be analytically described for simple round geometries. However, the forming of geometrically complex shapes can be predicted in advance only by the numerical simulations [5, 6] using the Finite Element Method (FEM) as a proven tool for evaluations of forming processes [7]. The FEM used for analyses of various metal forming applications [6] enables to cope complex material behaviour at different stress-strain states, material formability, crystallographic behaviour etc. up to the influence of strain rate and temperature of the formed part when forming at elevated temperatures is analysed [7, 8]. The coupling of different multi-physics phenomena like in the case of hot stamping simulations represents one of the most demanding topics of digital evaluation of forming processes [9]. Here also the appropriate techniques and hardware resources are necessary.

To raise the low formability limits of AHSS steels several concepts and technological improvements are presented in the literature. Kim et. al. worked on lubricants used in stamping process of AHSS [10]. In their work, they analysed the deep drawing and ironing process. Further on, the influence of the tool was analysed by the Mackensen et. al. at cutting of AHSS steels [11]. Similarly, Kim [12] and Cora [13] worked on the effects of different tool materials and various coatings as well as lubricants used in forming of AHSS materials.

An alternative approach for the increase of the formability of AHSS steels and other materials with low formability in cold state is to raise the temperature in forming process [1]. The hot stamping process is the most common solution for the increase of the formability of martensitic steels which express the lowest attainable elongation at room temperature [14, 15]. As already mentioned is this concept unfortunately not applicable to other AHSS steels where the material properties are achieved by combination of two or more crystallographic phases in the same material and heating above the recrystallization temperature would diminish their characteristics. Therefore, if the DP, CP or TRIP materials should be heated only to the level of warm working is a reasonable solution to improve the material formability, decreasing the level of flow curve and also lowering the forming forces. At the same time when using only the temperatures of warm forming, the material structure remains intact. Furthermore, the partial heating of blank only results in targeted local changing of material properties and softening the material in the area of large deformations. Local heating can be achieved by the laser beam heating [16] or with inductive preferential heating [17]. The later was selected as a heating solution in the research of deep drawing of DP600 steel at elevated temperatures. This is in particular important at deep drawing process where with the local heating of the flange area the formability is increased while at the same time unheated area below the punch could remain colder and material there has higher strength.

Application of flange heating is used in forming of several materials (which are brittle in cold forming conditions) using deep drawing as presented by Lehtinen et. al.[16].

In the presented study, the main focus is the FEM simulation of flange heating in deep drawing process in comparison with the experimental results presented by Kayhan [17].

Since one of the indicators to determine the material's formability of sheet metals is the deep drawing test performed as a round cup-drawing with a cylindrical punch - Figure 2. The diameter of the workpiece for the formed specimen is increased up to the fracture limit of drawn cup on its bottom. The obtained limit is called limit drawing ratio which is calculated as the ratio:

$$
\beta_{\text {max }}=\frac{D_{0}}{D_{p}}
$$

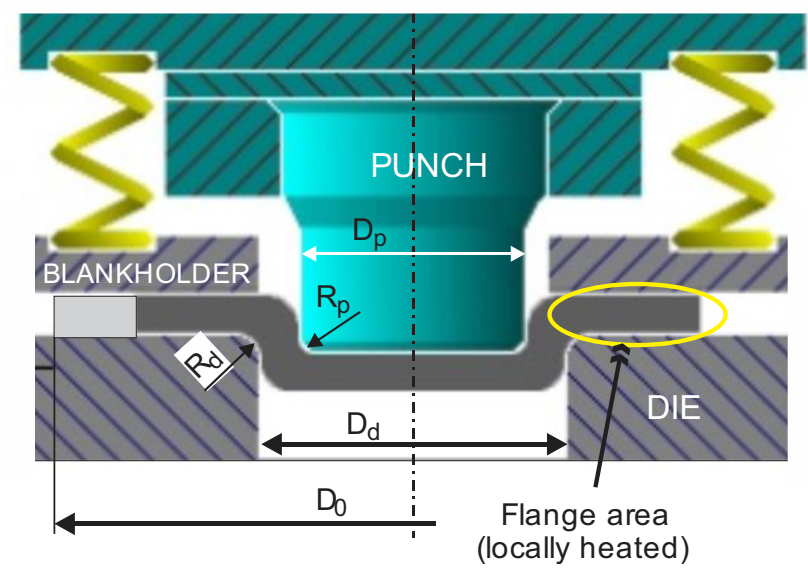

Figure 2. Schematic deep drawing of a round cup according to [18].

\section{Material}

The material considered in the experimental research and numerical simulations is sheet metal dual phase steel DP600 with thickness of $1.6 \mathrm{~mm}$ mostly used for the automotive applications at room temperature. The material is positioned in the softer third of the DP steels Figure 1. With its formability it delivers reasonable formability for forming analyses in cold and express necessary improvements of formability during the warm forming with locally heated flange area.

The forming properties of the used steel were analysed at room temperature and at elevated temperatures up to $300^{\circ} \mathrm{C}$. It can be expected that heating above the level of $300^{\circ} \mathrm{C}$ can start to change the crystallographic structure of the DP steel. Due to this reason, the $300^{\circ} \mathrm{C}$ temperature was selected as the upper working level of warm preferential heating during the deep drawing process. It needs to be considered that the limit of $300^{\circ} \mathrm{C}$ is suitable for inductive heating and plastic deformation simultaneously in the warm range. 
In order to obtain the flow curves for the DP 600 steel at room temperature and at elevated temperatures the uniaxial tensile tests were used. The tensile test at room temperature was performed on Zwick Z300 universal testing machine having $300 \mathrm{kN}$ nominal force.

The flow curves at elevated temperatures were performed parallel at Gleeble 1500 and Gleeble 3800 machines - Figure 3. The Gleeble 3800 machine has better performances while at Gleeble 1500 a selfdesigned extensometer placed direct on the specimen could be used to measure the elongation of the specimens very precisely. The flow curves were measured at room temperature, at $150^{\circ} \mathrm{C}, 200^{\circ} \mathrm{C}, 250^{\circ} \mathrm{C}$ and $300^{\circ} \mathrm{C}$ respectively. Additionally, the flow curves were measured at various strain rates ranging between 0.01 and 2.5 with following values: $\dot{\varepsilon}=0.01,0.1,1.0$ and 2.5 respectively.

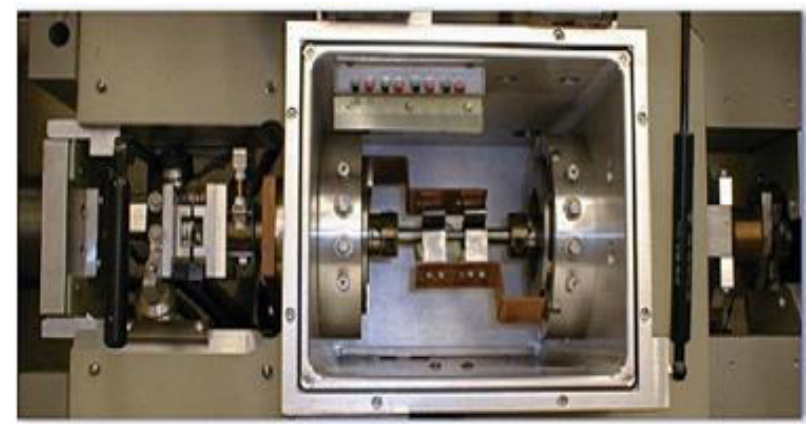

Figure 3. Gleeble 3800 testing machine.

Different temperature and strain rate combinations were verified in order to assure sufficient input data for the numerical simulations as well as to analyse the influence of the forming conditions on the level of the flow curve. It was found out that the flow curve at $150^{\circ} \mathrm{C}$ and $\dot{\varepsilon}=0.01$ differs only slightly from the flow curve at room temperature. With the temperature increase at small strain rates, the true stress of the flow curve decrease but the drop of the flow curve level is more evident at higher strain rates where it reaches down to $80 \%$ of the level at room temperature. At strain rates of $\dot{\varepsilon}=2.5$, also the attainable maximal elongation drops with the temperature - Figure 4 - in comparison to the room temperature flow curve performed at $\dot{\varepsilon}=0.01$. It was found out that at higher strain rates, the flow curves in the range between $200^{\circ} \mathrm{C}$ and $300^{\circ} \mathrm{C}$ are very similar. At lower strain rates this phenomena was not so drastically emphasised. Furthermore, the data from the tensile test are only the base data for the material characterisation and further analysed need to be performed for comprehensive material behaviour at elevated temperatures. From Figure 4, it is also evident that at elevated temperatures with high strain rates the attainable elongation is also decreased in comparison to the flow curve at room temperature obtained with significant lower strain rates. Last but not least, the anisotropic material behaviour was not yet implemented at this research level since the rotational-symmetric case was analysed by FE method.

\section{FE model}

The flow curves obtained experimentally were implemented into the FEM program ABAQUS in order to simulate the preferential heating of the flange during the deep drawing of a round cup.

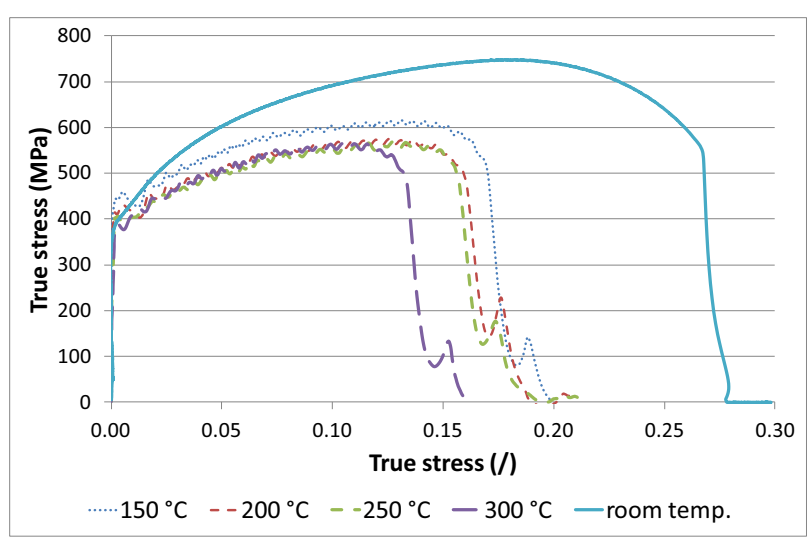

Figure 4. Tensile tests at room temperature $(\dot{\varepsilon}=0.01)$ and at elevated temperatures ( $\dot{\varepsilon}=2.5$ ).

Numerical simulations were comparatively evaluated with the experimental work in order to obtain a reliable tool for further predicting of locally heated forming behaviour of DP steels and other interesting materials at elevated temperatures formed below the temperature of recrystallization.

The FE data of round cup were set-up as rotationalsymmetric simulation since the anisotropic material behaviour was neglected at this research level. The FE model consists of:

- Geometrical data

- Mechanical properties

- Temperature and strain rate dependant formability properties (flow curves)

- Thermal properties (conductivity, heat transfer, etc.)

- Contact conditions between tool and the workpiece

- Boundary conditions (initial temperatures, temperatures during the forming, blankholder force, ram speeds during deep drawing).

The finite element (FE) model consists of heated die, heated blankholder, local heated blank flange, cooled punch, and cooled central area of the blank - Figure 5 (top). In order to shorten the calculation times, the thickness of the die and the blankholder were decreased in comparison to the real tool geometry. Experimentally the temperature was measured at the die radii of $56 \mathrm{~mm}$ and $21 \mathrm{~mm}$ respectively as presented on Figure 5 (bottom). Between the heated die and blankholder the temperatures of $260^{\circ} \mathrm{C}$ was measured while at the drawing radius $R_{d}$ only $180^{\circ} \mathrm{C}$ was measured. For the simulation, the heated zones between above determined radii were divided into ten sections on the die and the blankholder with sequential increasing of the 
temperature. The punch was considered as semi-cold with the contact temperature of $80^{\circ} \mathrm{C}$ during the heating of the flange area. The bottom of the inner part of the specimen is cooled with the water spray - Figure 5 - during the drawing process. Therefore, in this area the surface temperature was assumed to be $40^{\circ} \mathrm{C}$ during the deep drawing.
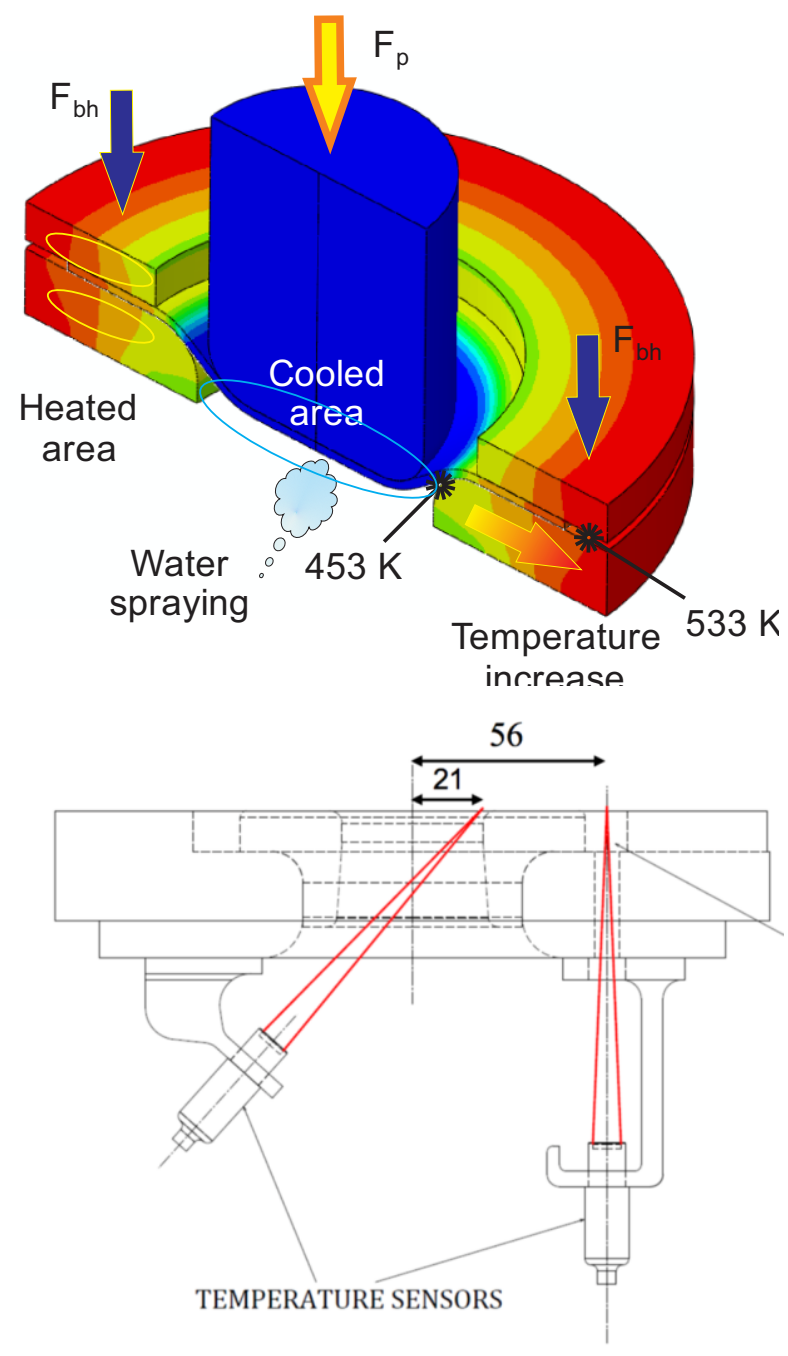

Figure 5. Concept of the sequential heating of the die and the blankholder (top) and the location of temperature sensors at experimental set-up (bottom).

The FEM model consists of fully thermo-elastoplastic simulation where also the tool parts are considered as thermo-elastic. The sheet thickness of $1.6 \mathrm{~mm}$ was divided into 5 layers of rotational-symmetric elements. The model of the tool parts and the blank is meshed with CAX4RT elements. The mesh of the FEM model of a blank having $\varnothing 96 \mathrm{~mm}$ in diameter and the drawn cup are presented on Figure 6 prior (top) and after the deep drawing (bottom).

Numerical simulation was performed in three steps: heating of the entire system by the temperature increase at the blankholder and the die, deep drawing and springback analysis. Despite the springback in the flange is minimised through the heating it still needs to be analysed in order to verify its influence on residual stresses.
Numerical simulation of the deep drawing process with localised heating shows that the sequential heating through the entire die and blankholder thickness delivers good heat distribution prior to the drawing process observed by temperature distribution of individual nodes as shown on Figure 7. All temperatures in the FE model are considered and visualised in degrees of Kelvin.

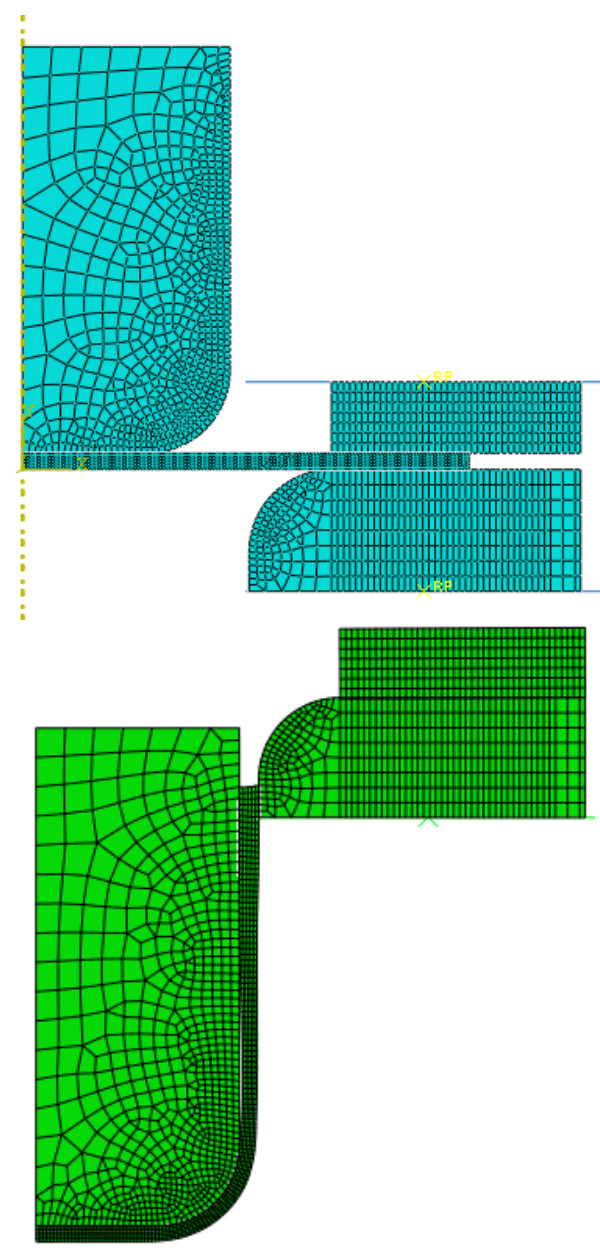

Figure 6. FEM mesh of the deep drawn cup: initial state (top) and after the drawing process (bottom).

The explicit simulation of the deep drawing process was performed without any time acceleration or mass scaling using the true ram speed calculated according to the data of the applied mechanical (eccentric) press.

In order to determine the maximal attainable blank diameter which could be successfully drawn with the heating of the flange area following blank diameters were analysed: $88 \mathrm{~mm}, 90 \mathrm{~mm}, 92 \mathrm{~mm}, 94 \mathrm{~mm}, 96 \mathrm{~mm}, 98$ $\mathrm{mm}, 100 \mathrm{~mm}, 101 \mathrm{~mm}$, and $102 \mathrm{~mm}$ respectively. The heated flange area of the specimens was lubricated with graphite and/or politetrafluoretilen (PTFE) foil. The friction coefficient for this lubricants was experimentally determined and varies between $\mu=0.035$ and $\mu=0,055$. For the PTFE foil also friction coefficients at elevated temperatures were determined. The values are ranging between $\mu=0.02$ and $\mu=0.035$ and are vary with the temperature. The lowest friction coefficient express PTFE at $200^{\circ} \mathrm{C}$ while with further increase of the temperature the friction coefficient increase as well. This 
can be explained with extensive softening of PTFE foil having its melting point at $326.8^{\circ} \mathrm{C}$. When using this lubricant for warm deep drawing the melting point of PTFE represent additional temperature limitation beside the crystallographic structure of DP600 steel.

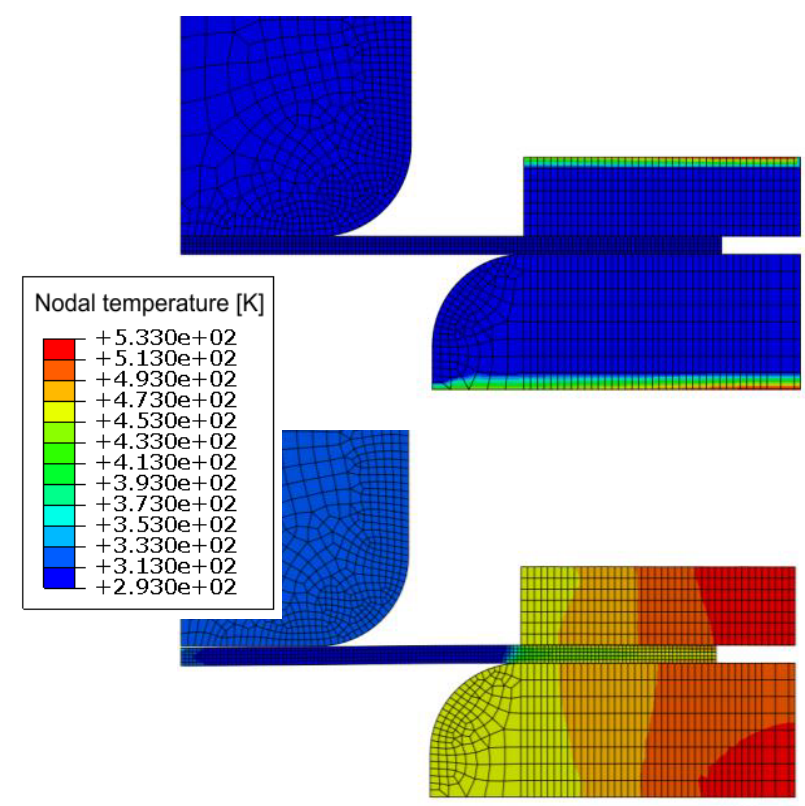

Figure 7. Nodal temperature distribution at the differential heating of the flange - initial stage (top) and at the end of the heating phase (bottom).

The unheated specimen area below the punch was not lubricated. Therefore, the friction coefficient of $\mu=0.15$ was selected here.

The locally heated flange expresses lower stresses and through this improved formability in comparison to the forming at room temperature. This results in higher attainable drawing ratios in comparison to the room temperature conditions. Additional to the inductive heating prior to the forming operation the material heats due to the plastic strains. Therefore, the temperature in the preliminary heated area increases during the deep drawing process. Figure 8 shows the temperature distribution during the deep drawing for the specimen with the diameter of $\varnothing 96 \mathrm{~mm}$.

The comparative analyses with different blank diameters have shown that with the temperature variable friction coefficient in the flange area the largest successfully drawn diameter is $\varnothing 100 \mathrm{~mm}$ while the cups with larger diameters of $101 \mathrm{~mm}$ and $102 \mathrm{~mm}$ were torn at the cup bottom - Figure 9 .

The evaluation of the springback shows, that the springback has geometrically the highest influence on the cup diameter at its top edge which change with the relaxation outside of the tool. The relaxation of the specimen with a blank diameter of $\varnothing 98 \mathrm{~mm}$ and the diagram with values for various drawing ratios are presented on Figure 10. It is obvious that the springback effect has only a minor role from the geometrical point of view and could be neglected in further analyses.
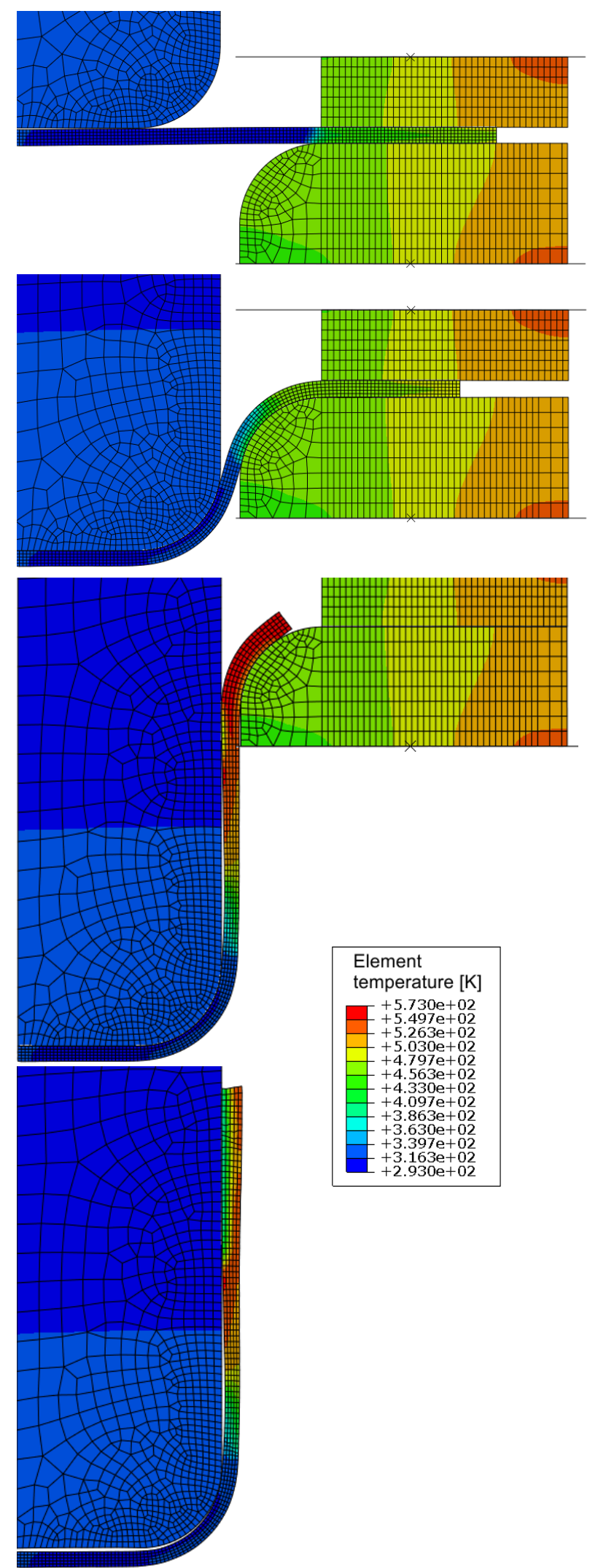

Figure 8. Temperature distribution during the forming process.

Obtained results have been compared with experimental data of deep drawn cups. In particular the maximal drawing ratio was evaluated which is mainly influenced by the proper determination of the flow curves at elevated temperatures and friction coefficient in the flange area of the drawn cup. 

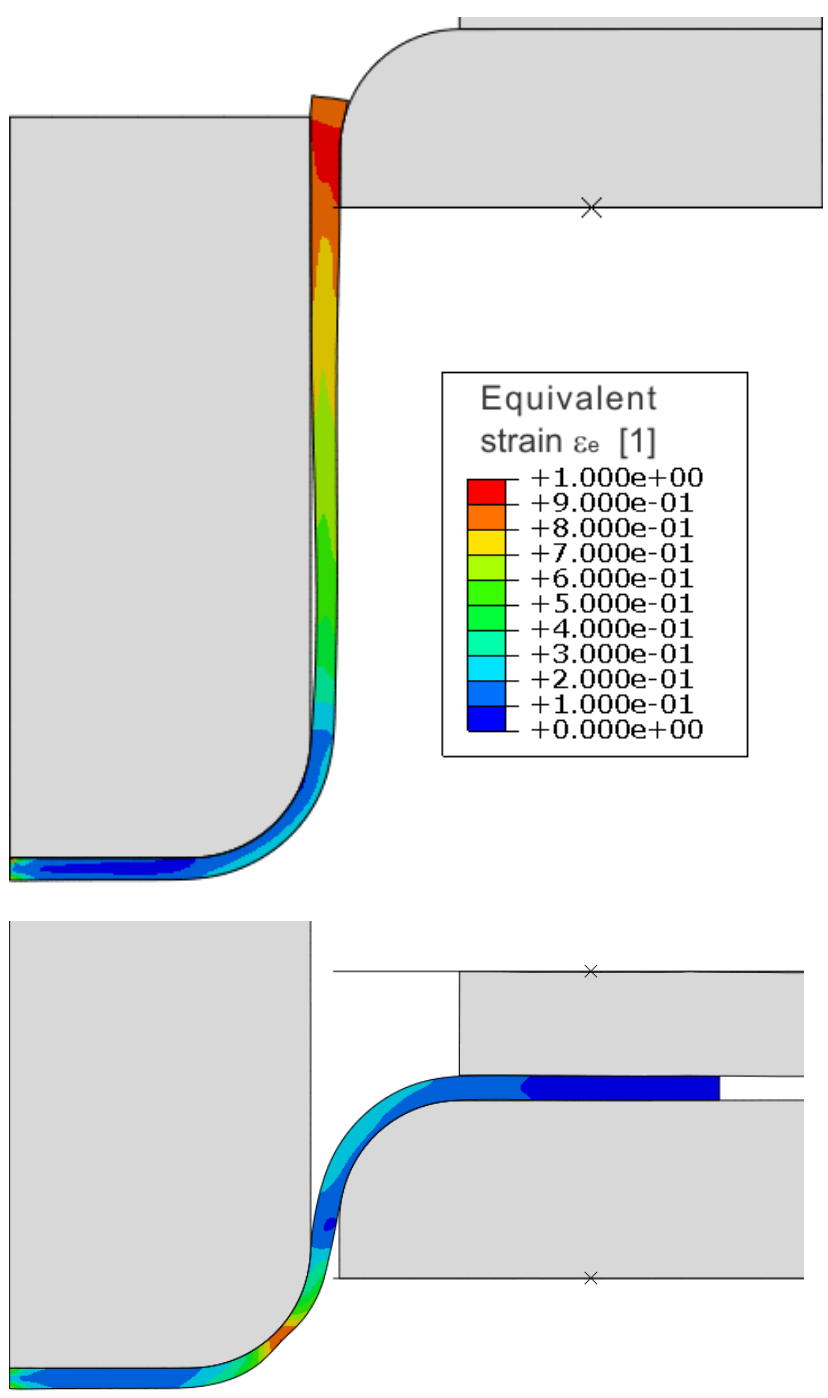

Figure 9. Strain distribution at deep drawing: blank diameter $\varnothing 100 \mathrm{~mm}$ (top) and Ø102 mm (bottom).

\section{Experimental verification}

The experimental verification of the performed FE simulations was performed on special adopted heated device positioned on the eccentric press [17] - Figure 11. The heating was provided by the inductance coil inserted in the die while the cooling of the central area of the blank was assured by spraying the water from the bottom side. The data of drawn specimens at various conditions are presented in Table 1.

Experimentally obtained succesful drawn parts are presented in Figure 12 together with the drawing data obtained by the numerical simulation. It is evident that the limiting drawing ratio obtained with experiments is comparable with numerical results for the analyses at room temperature. At elevated temperatures, the experimentally obtained limit drawing ratio of DP600 steel is higher than the limit obtained by the numerical simulations.

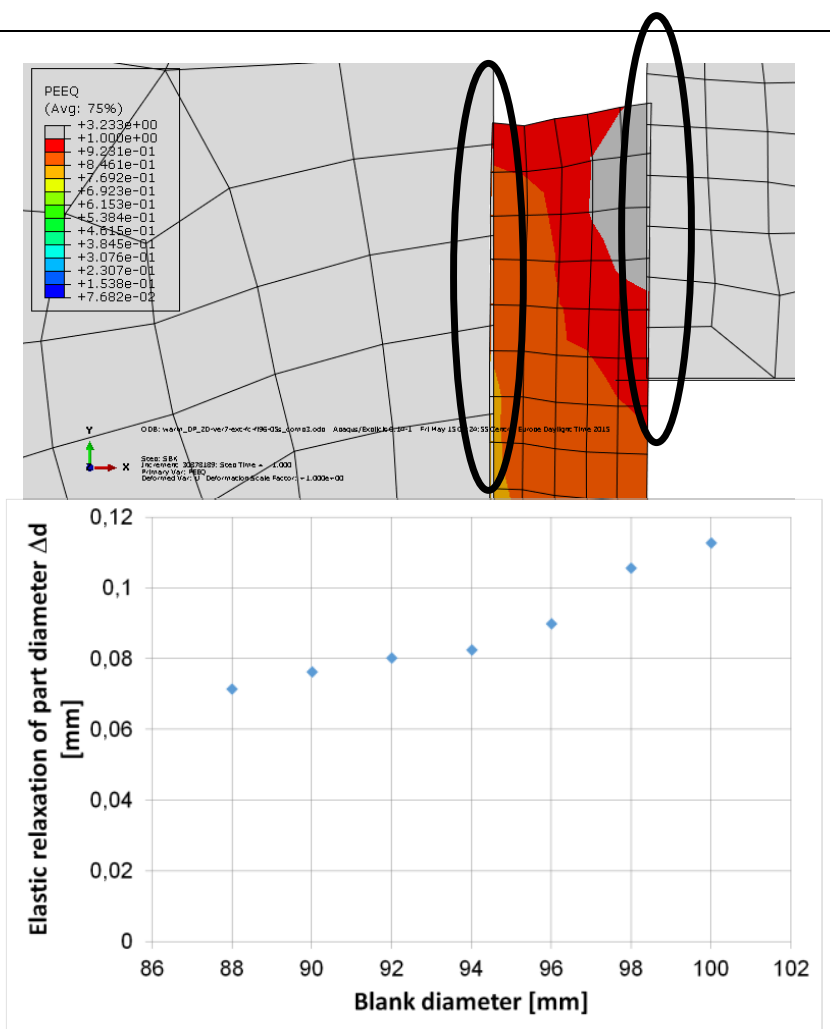

Figure 10. Elastic distortion for the cup drawn from the blank of $Ø 98 \mathrm{~mm}$ (top) and correlation of springback versus drawing ratio (bottom).

Table 1: Experimental data of heated deep drawing [17].

\begin{tabular}{|c|c|c|c|c|}
\hline $\begin{array}{c}\text { Blank } \\
\text { diameter } \\
(\mathrm{mm})\end{array}$ & $\begin{array}{c}\text { Lubricant / } \\
\text { Temperature }\end{array}$ & $\beta(/)$ & Condition & $\begin{array}{c}\text { Max. } \\
\text { Force } \\
(\mathrm{kN})\end{array}$ \\
\hline 84 & Graphite / Room & 2.05 & OK Room & 130.3 \\
\hline 86 & Graphite / Room & 2.10 & OK Room & 136.4 \\
\hline 88 & Graphite / Room & 2.15 & Room limit & 132.8 \\
\hline 90 & Graphite / High & 2.20 & OK High Temp & 120.2 \\
\hline 94 & Graphite / High & 2.30 & OK High Temp & 131.5 \\
\hline 96 & Graphite / High & 2.35 & OK High Temp & 134.1 \\
\hline 98 & $\begin{array}{c}\text { Graphite + PTFE } \\
/ \text { High }\end{array}$ & 2.40 & OK High Temp & 135.2 \\
\hline 102 & $\begin{array}{c}\text { Graphite + PTFE } \\
/ \text { High }\end{array}$ & 2.49 & OK High Temp & 132.9 \\
\hline 104 & $\begin{array}{c}\text { Graphite + PTFE } \\
/ \text { High }\end{array}$ & 2.54 & OK High Temp & 135.1 \\
\hline 106 & $\begin{array}{c}\text { Graphite + PTFE } \\
\text { / High } \\
\text { Graph+Tefl }\end{array}$ & 2.59 & $\begin{array}{c}\text { High Temp } \\
\text { Fail }\end{array}$ & -- \\
\hline
\end{tabular}

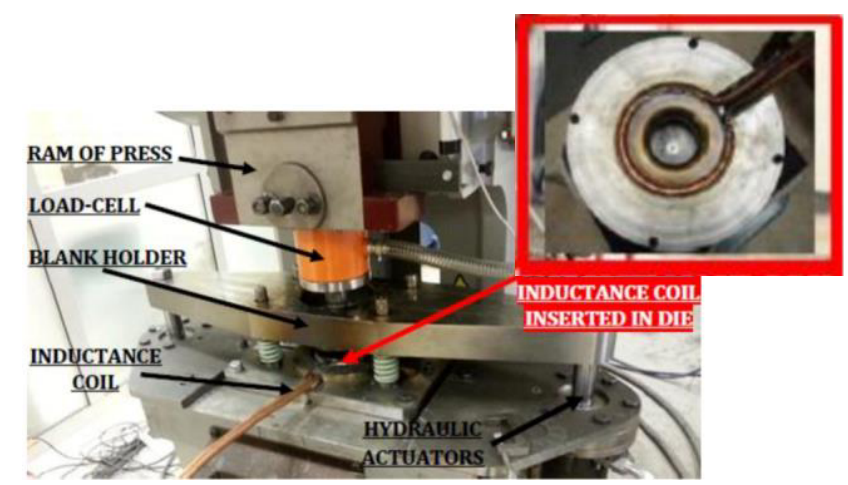

Figure 11. General construction showing the inductance heating device in the die [17]. 


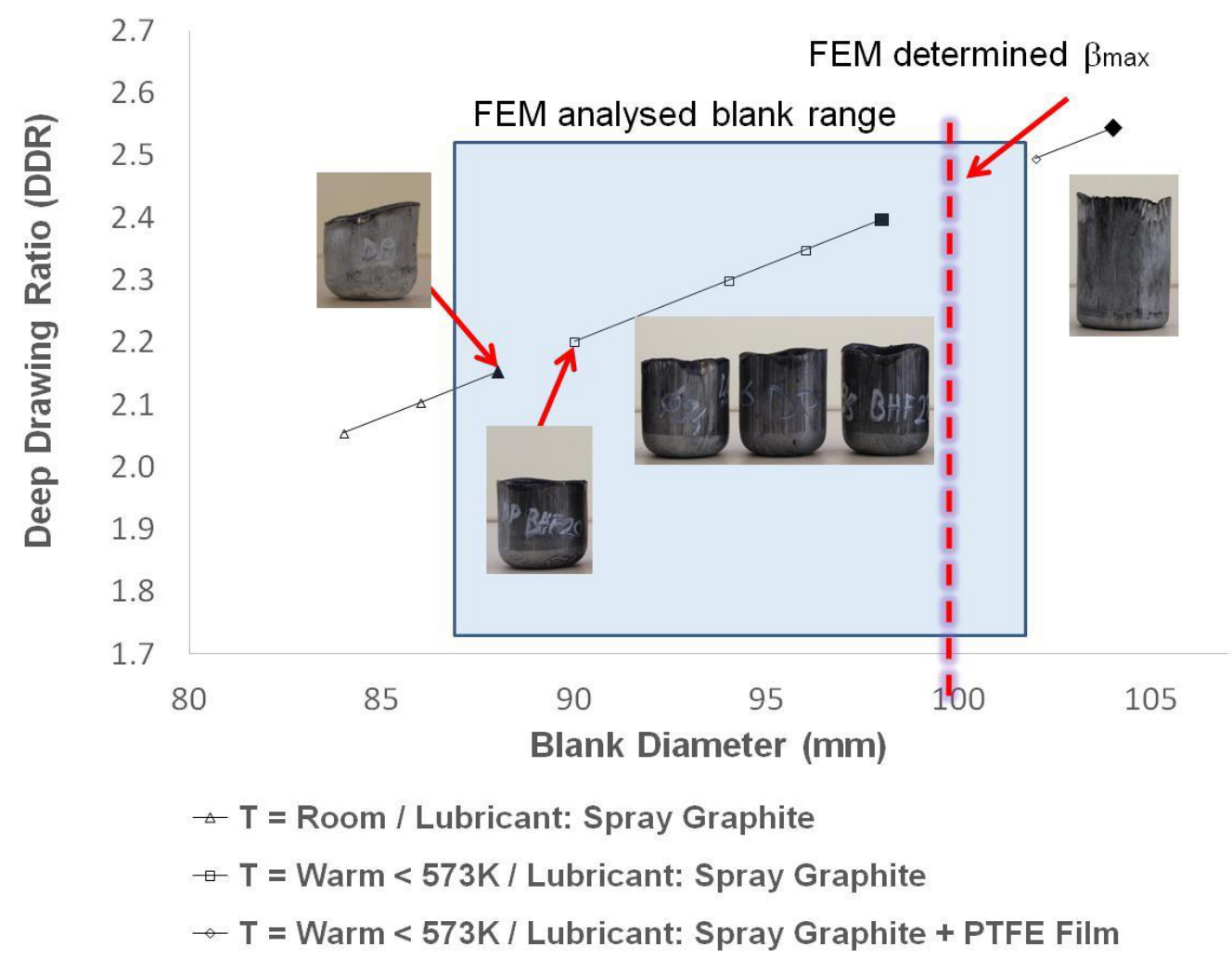

Figure 12. Experimentally obtained maximal drawing ratios with graphite lubrication.

\section{Conclusion}

In presented work, simulations of preferential flange heating at deep drawing of round cup are performed and compared with experimentally obtained results. The input parameters for the simulation were determined experimentally; in particular the material behaviour at room temperature and at elevated temperatures up to $300^{\circ} \mathrm{C}$. Additionally, friction coefficient and its temperature dependence for PTFE foil was determined in a range of $\mu=0.02$ to 0.035 . By applying the PTFE foil the experiments are limited to $300^{\circ} \mathrm{C}$ since the solid film lubricant has its melting point at $326.8^{\circ} \mathrm{C}$.

Flow curves for DP600 were analysed for various temperatures and strain rates. The increase in temperature up to $300^{\circ} \mathrm{C}$ decrease the level of flow curves what is in particular emphasised when the high strain rates are considered. The highest decrease of flow curve was observed $\varepsilon=2.5$. However, performed simulations have shown that the strain rates in the flange region rarely exceed the value of $\dot{\varepsilon}=1$. Therefore, extensive measurements of flow curves for strain rates below $\dot{\varepsilon}=1$ needs to be performed.

Numerical simulations were performed with explicit FEM solver using fully thermo-elasto-plastic model of the tool and the formed specimen. Simulations were carried out in three steps included thermal heating, deep drawing process and springback analysis. The flange region was heated to $260^{\circ} \mathrm{C}$ in its outer region and to $180^{\circ} \mathrm{C}$ on the die radius with graduate temperature decrease between both limiting values.

Numerical simulations have shown increase of maximal drawing ration from 2.15 obtained at room temperature up to 2.45 obtained with the heated flange area.

Experimental analyses with heated tool have shown even higher limits of the drawing ratio reaching the value of $\beta_{\max }=2.54$ for the observed DP600 material with sheet thickness of $1.6 \mathrm{~mm}$. This represents an increase of $18.18 \%$ of the maximal drawing ratio in comparison to the forming at room temperature.

In order to improve the fit of numerical and experimental results, additional evaluation of the flow curves as well as the behaviour of the solid lubricants at elevated temperatures needs to be performed.

Here presented research work has shown promising influence on increase of material draw ability with a local heating of the flange area in the temperature range between $200^{\circ} \mathrm{C}$ and $300^{\circ} \mathrm{C}$. Further research will be dedicated to the analyses of non-rotational parts demanding also additional extensive computer resources for thermo-elasto-plastic analyses.

\section{Acknowledgements}

The authors would like to acknowledge the financial support received from The Scientific and Technological Research Council of Turkey (TUBITAK) and Slovenia(ARRS) under Project No: 111M448 and from ATILIM University under the project No: ATÜ-BAP1011-13. The use of facilities in the Metal Forming Center of Excellence at ATILIM University as well as 
Faculty of Natural Sciences and Engineering, University of Ljubljana is also acknowledged and thanks are extended to the personnel for their contributions on the material tests and the use of HPC.

\section{References}

1. S. Sadagopan, D. Urban, American Iron and Steel Institute/Department of Energy Technology Roadmap Project TRP\#0012 (2003)

2. N.N.: Advanced High-Strength Steels application guidelines Version 5.0, WorldAutoSteel (2014)

3. H. Aydin, E. Essadiqi, I.-H. Jung, S. Yue, Mat. Sci. \& Eng., A 564, 501-508 (2013)

4. R. Krupitzer, AHSS Technology Workshop Southfield MI, Steel Market Development Institute (2012)

5. K. Bandyopadhyay, S.K. Panda, P. Saha, G. Padmanabham, J. Mat. Proc. Technol., 217, 48-64 (2015)

6. G. Ingarao, R. Di Lorenzo, F. Micari, Mat. \& Design, 30, 4421-4433 (2009)

7. A.E. Tekkaya et. all, CIRP Annals , 64, 629-653 (2015)

8. C. Lei, J. Cui, Z. Xing, H. Fu, H. Zhao, , Phys.Proc. 25118 - 124 ( 2012 )

9. R.K.Verma, P.Biswas, T. Kuwabara, K. Chung, Mat. Sci. \& Eng. A, 604 98-102 (2014)

10. H. Kim,T. Altan, Q. Yan, J. Mat. Proc. Technol., 209, 4122-4133 (2009)

11. Mackensen, M. Golle, R. Golle, H. Hoffmann, CIRP Annals 59, 283-286 (2010)

12. Kim, H., Han., S., Yan, Q., Altan, T., CIRP Annals, 57, 299-304 (2008)

13. Ö.N. Cora, A. Ağcayazı, K. Namiki, H. Sofuoğlu, M. Koc, Tribol. Int. 52, 50-60 (2012)

14. A. Abdollahpoor, X. Chen, M. P. Pereira, N.Xiao, B.F. Rolfe, J. Mat. Proc. Technol., 228, 125-136 (2016)

15. M. Merklein, M.Wielanda, M. Lechnera, S. Bruschib,A. Ghiotti, J. Mat. Proc. Technol., 228, 11-24 (2016)

16. P. Lehtinen, T. Väisänen, M. Salmi, Phys. Proc., 78, 312-319 (2015)

17. E. Kayhan, The development of a method to improve the limit drawing ratio of blanks using preferential heating, Ph.D. Thesis, Atılım University, Turkey (2015) 